\title{
Perforation and bleeding during an underwater endoscopic mucosal resection of a large colonic lesion
}

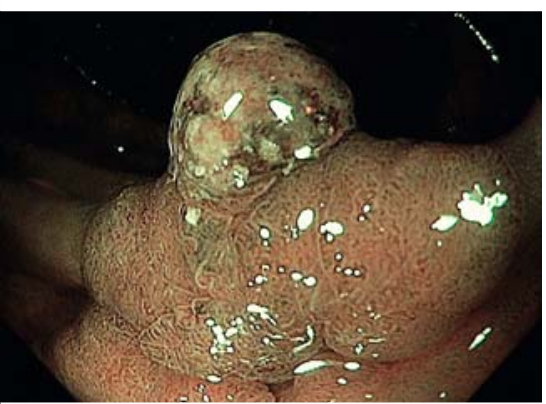

- Fig. 1 A $2.0 \mathrm{~cm}$-lesion $(0-$ Ila + Is) at the transverse colon (narrow-band imaging).

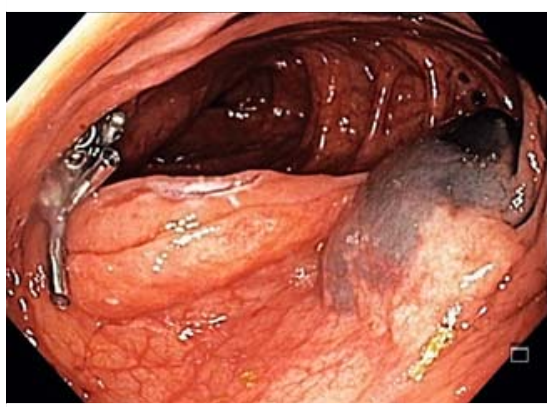

Fig. 4 Endoscopic appearance after hemostasis, through-the-scope clip closure, and endoscopic tattoo.

Underwater endoscopic mucosal resection (UEMR) is a well-established endoscopic technique for the resection of colorectal lesions in general; it is known to be safe and effective [1]. Water immersion provides a "floating" effect of the mucosa and submucosa, keeping them apart from the muscularis propria and allowing a deep yet safe resection. It has been proved to be cost-effective (in comparison to the standard EMR technique) because it does not require a submucosal injection and is also extremely helpful for resecting large colorectal lesions as well as those with a prominent fibrotic component as seen in recurrent lesions.

Bleeding - either early or delayed - and perforation are the most feared complications of endoscopic resection tech-

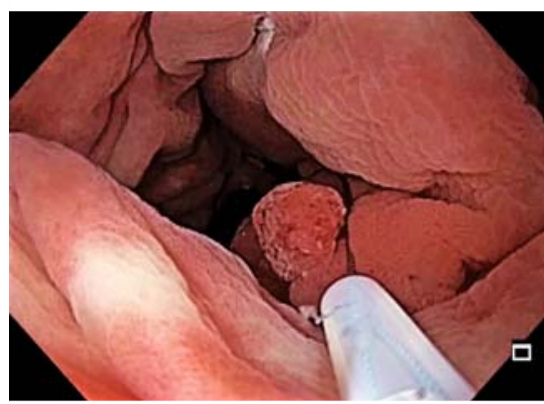

- Fig. 2 Underwater endoscopic mucosal resection (EMR) technique.

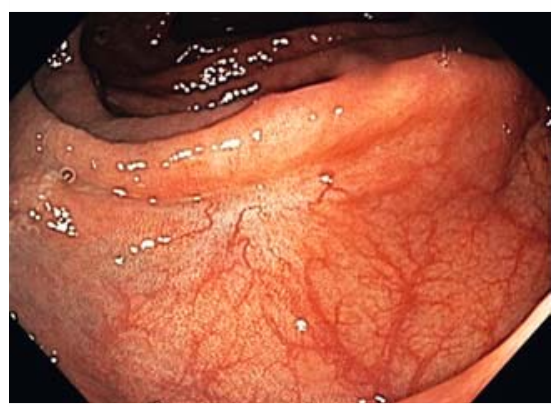

Fig. 5 Follow-up after 6 months.

niques in general. UEMR has shown exceptionally low rates of complications, with no perforations described in the most recent publications and delayed bleeding in only $5 \%[1-4]$. Bleeding during endoscopic resection has been more commonly reported. However, in most cases, only small persistent bleeds, easily managed during the procedure, occurred.

A 75-year-old woman was diagnosed with a $2.0-\mathrm{cm}$ neoplastic lesion (0-Ila + Is) at the transverse colon during a screening colonoscopy ( Fig.1). An underwater EMR technique was performed ( $\triangleright$ Fig. 2 ). Immediately after the procedure, both active bleeding and perforation were detected ( $\mathbf{F i g . 3}$ ). Hemostasis at the bleeding site was achieved with thermal coagulation, and the perforation was suc-

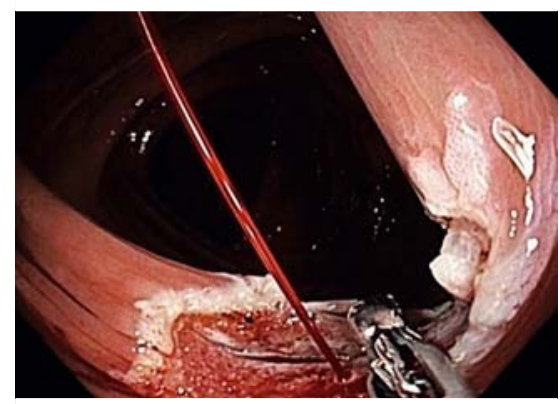

- Fig. 3 Bleeding and perforation after underwater endoscopic mucosal resection (EMR).

cessfully treated with through-the-scope clips. An endoscopic submucosal tattoo was placed near the resection site to facilitate a future surgical procedure in case of failure of the endoscopic closure attempt (> Fig.4).

The patient remained under clinical observation and received antibiotic therapy with ciprofloxacin and metronidazole. After 1 day she was discharged with no symptoms or signs of complication. A control colonoscopy was performed 6 months after the procedure and showed no signs of recurrence ( $\mathbf{F i g . 5}$ ).

Endoscopy_UCTN_Code_CPL_1AJ_2AD

Competing interests

The authors declare that they have no conflict of interest.

The authors

José Luiz Paccos, Daniela Suppo de Oliveira, Fernando J. S. de Oliveira, Eduardo M. A. Pereira Junior, Fernando L. Mota, Mayara M. C. da Silva', Paulo Alberto F. P. Corrêa Department of Digestive Endoscopy, Hospital Sírio-Libanês, São Paulo, Brazil 


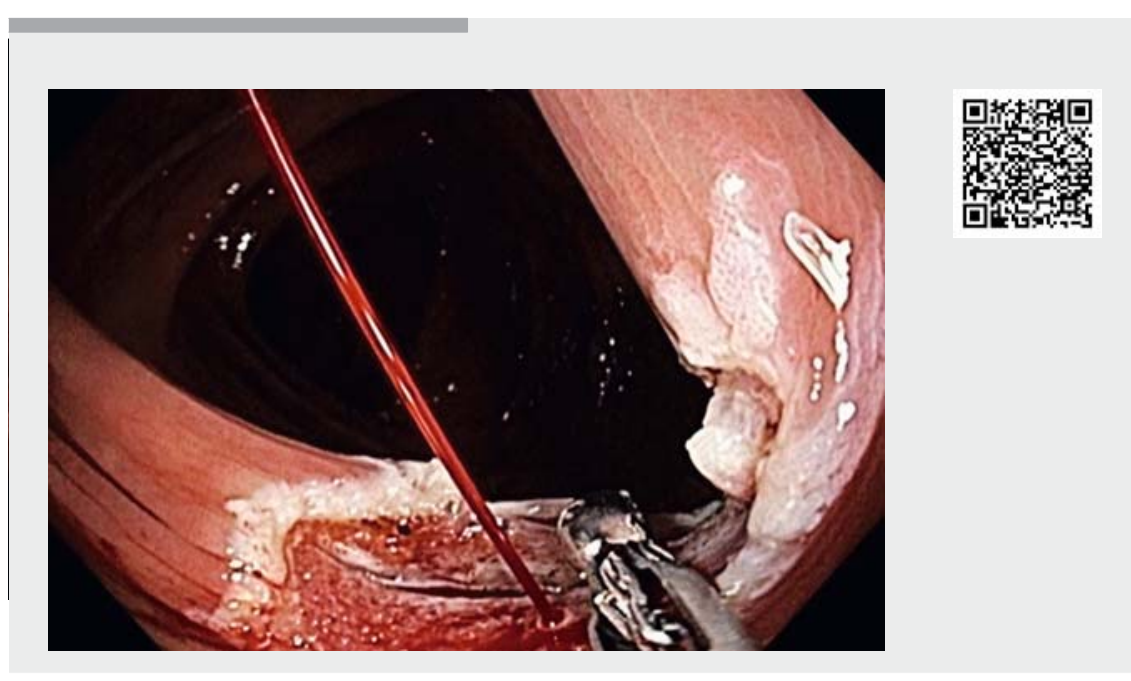

Video 1 Perforation and bleeding during an underwater endoscopic mucosal resection of a large colonic lesion.

\section{Corresponding author}

\section{Fernando L. Mota, MD}

Department of Digestive Endoscopy, Hospital Sírio-Libanês, Rua Dona Adma Jafet, 91, São Paulo, Brazil

Fax: +55-11-3394-0568

landerfernando@hotmail.com

\section{References}

[1] Binmoeller KF, Weilert F, Shah J et al. Underwater EMR without submucosal injection for large sessile colorectal polyps (with video).
Bibliography

Endoscopy 2021; 53: E326-E327

DOI 10.1055/a-1275-9832

ISSN 0013-726X

published online 23.10 .2020

(C) 2020. Thieme. All rights reserved.

Georg Thieme Verlag KG, Rüdigerstraße 14, 70469 Stuttgart, Germany

\section{ENDOSCOPY E-VIDEOS}

https://eref.thieme.de/e-videos

回回 Endoscopy E-Videos is a free access online section, reporting 靣转: on interesting cases and new techniques in gastroenterological endoscopy. All papers include a high quality video and all contributions are freely accessible online.

This section has its own submission website at https://mc.manuscriptcentral.com/e-videos
2] Uedo N, Nemeth A, Johansson GW et al. Underwater endoscopic mucosal resection of large colorectal lesions. Endoscopy 2015; 47: 172-174

[3] Wang AY, Flynn MM, Patrie JT et al. Underwater endoscopic mucosal resection of colorectal neoplasia is easily learned, efficacious, and safe. Surg Endosc 2014; 28: 1348-1354

[4] Curcio G, Granata A, Ligresti D et al. Underwater colorectal EMR: remodeling endoscopic mucosal resection. Gastrointest Endosc 2015; 81: 1238-1242 